\title{
Climate-Based Daylighting Metrics Assessment to Select among Optimum Energy Efficient Windows' Shading Devices Solutions: a case study of an office in a hot climate
}

\author{
Ali F. Alajmi ${ }^{1}$, Faris Abaalkhail ${ }^{2}$, Adnan Alanezi ${ }^{2}$ \\ ${ }^{1}$ Mechanical Engineering Department, College of Technological Studies, PAAET, Kuwait \\ ${ }^{2}$ Architecture Department, College of Architecture, Kuwait University, Kuwait
}

\begin{abstract}
Window's external shading is playing a major role in preventing unwanted direct solar gain. Thus, the main objectives of this study are to optimize the fixed windows' shading type (overhang with sided-fins, simple overhang, and louvers) for the four main orientations (East, West, North, and South) using Genetic Algorithm (GA).

The findings show savings in East by $27 \%, 25 \%$, and $24 \%$ for the overhang with sided-fins, simple overhang and louvers respectively. Therefore, to select among the optimum energy efficient solutions, climate-based daylighting metrics were utilized to assess the daylighting availability. The other orientation were straightforward were the results in favor of overhang with sided-fins.
\end{abstract}

\section{Introduction}

Buildings consume $40 \%$ of the annual world energy and even larger in sever hot climate countries. For example, buildings in the State of Kuwait account for $70 \%$ of the electrical power consumed at peak time in summer days (ME, 2005). One of the main factors that contribute to buildings heat gain is direct solar gain through windows. Building design in Kuwait is usually carried out by the owner preference. Windows configuration and its effect on energy use are rarely concerned during the design stages. Such decisions which are ignored at an early stage are hard to change later. In fact, buildings owners are fascinated by how transparent their buildings are, regardless of their severe energy use consequences.

Therefore, the influence of the windows design choices (including shading strategies) has to be evaluated completely based on energy perspective and visual comfort. This can be accomplished by minimizing energy use for heating, cooling, and electric lights along with increasing the natural light (daylight) to its maximum possible availability. Such an approach requires particular coupling of building simulation program and an optimization algorithm; this is referred to by building the simulation-based optimization technique (BSOT). Thus, in this study "state-of-the-art" EnergyPlus (Crawley et al., 2001) is linked with a Genetic Algorithm (GA) to achieve such an approach.

In this study, the input variables to the simulation program represent the shading device design elements such as projection and inclination of shading devices. Simultaneous changing of these parameters will lead to different possible solutions. These possible solutions (search space) can be searched systematically by an optimization method. The search space in this study had been directed by the two main objectives, which are minimizing energy use and maximizing daylighting.

In this paper, the building simulation-based optimization technique (BSOT) is utilized to get the optimum window's shading devices. The best solutions are further assessed by using climate-based daylighting metric as post-processing to consider the annual daylighting availability.

\section{Building a Simulation-based Optimization Technique}

Many types of research have proven that the building simulation-based optimization approach can improve building energy efficiency and indoor environment (Caldas and Norford, 2001; More and Wright, 2003). In order to implement a building simulation-based optimization technique (BSOT); an optimization algorithm has to be coupled with a building simulation program such as EnergyPlus, BSIM, and DOE-2. In this research, the Genetic Algorithm was selected as an Evolutionary Algorithm (EA) to implement the search while, EnergyPlus was chosen to simulate the building.

\section{Evolutionary Algorithm (Genetic Algorithm)}

In natural law, strong genes will survive for many generations. Similarly, in artificial creatures, a random set of chromosomes (population) is initiated first, which represents initial solutions to the studied problem. Then, an evolution to that initial population takes place, using reproduction operators: selection, crossover, and mutation (Goldberg, D.E., 1989). A selection operator is invoked to create a new intermediate population of parents, where the probability for each individual to survive is in linear proportion to its fitness value. Basically, above average individuals will be most likely to have more copies in the intermediate population, while below average individuals will be at risk of being discarded. After the population of parents has been selected, a reproduction operator is applied to produce the new offspring. Then a fine alteration of the new chromosomes is appealed by what is called a mutation operator; GA process is illustrated in Figure 1.

From the above description, the reproduction looping will keep continuing forever, forming an infinite loop. However, this process is terminated if one of the 
following four conditions is satisfied: a) a good solution is found, b) a certain number of generations or function calls have been reached, c) a set time has elapsed, or d) no improvement has taken place in the solution.

In this study, initial trails of different population sizes have been tried to ensure the search not trapped on local optimum solutions or run longer than it is needed. The trials revealed that a GA of a relatively small size population (size 15) with a high reproduction rate, 100\% crossover, and $20 \%$ mutation rate with a fixed number of generations (100) are the efficient combination selection. Such GA configuration agreed with the findings of Alajmi and Wright (2014).

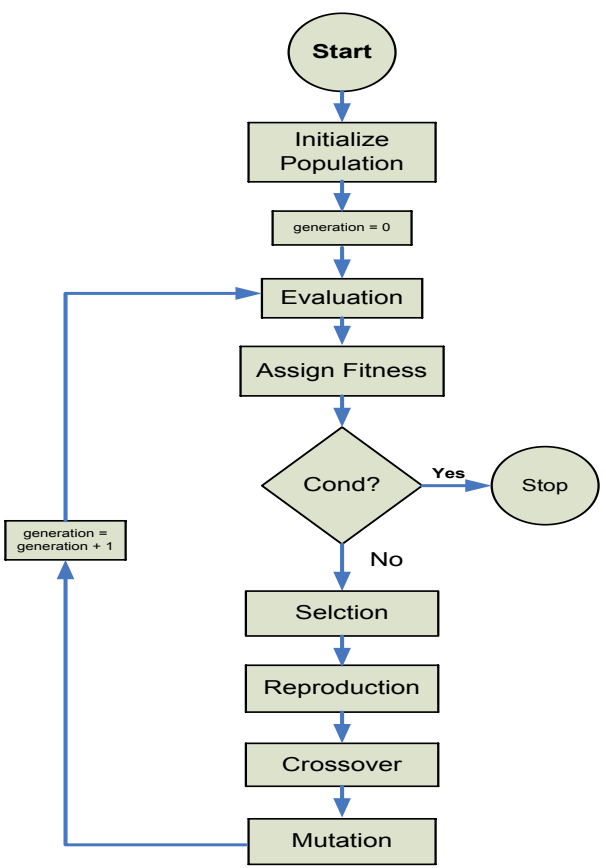

Figure 1: Basic Genetic Algorithms (GAs) flowchart.

\section{Building Simulation Program (EnergyPlus)}

This new-generation building energy simulation program is the outcome of more than two decades of developments by the U.S. Department of Energy (Crawley et al., 2001). One of the major features of EnergyPlus is the integration between the building loads, system and plant. This feature allows accurate space temperature predictions using the Predictor-Corrector Method. This method predicts the mechanical system load needed to maintain the zone air set point and simulates the mechanical system to determine its actual capacity. Then, it recalculates the zone air-heat balance to determine the actual zone temperature. Numerous research projects have validated the performance and accuracy of the EnergyPlus (Olsen and Chen, 2003).

In this study, the program calculates the heating, cooling, lighting, and equipment consumptions and visual comfort.

\section{Research Methodology}

Optimizing any scientific problem requires an extensive evaluation of the objective function. In the case of building optimization problem, a massive number of building simulations are required to be evaluated. This may be one of the main obstacles of using the simulation- based technique. For instance, in this research eight design parameters are assigned to be varied on different step size (bounds); this turned into 1104 possible solutions for each orientation $(4 \times 1104=4416)$.

To overcome such an obstacle, the following approaches may be implemented: a) using parallelized method through the network, b) storing the evaluated solution is saved in a database or virtual memory so as not to reevaluate the similar solutions, c) simplifying the objective function and/or its constraints.

In this study, the first three mentioned above approaches are considered. Precisely, the most effective approach is parallel function calls (building simulations). This requires a high-performance computing machine. Therefore, a server of 48 threads (ENSIMS X3200) powered by $2 \mathrm{x}$ Intel Xeon $2.5 \mathrm{GHz}$ with a memory size of 64GB RDIMM was allocated to accomplish the computation. This powerful machine (server) enables multi-tasking simulations, up to 56 at the same time.

\section{Design Parameters}

The design parameters and its bound values need to be selected carefully to an increase the computational time. The selected design parameters in this study are as follows: 1) the overhang projection which is set from zero to half of the window height $(\mathrm{H}), 2$ ) its inclination (tilt) from $90^{\circ}$ to $135^{\circ}\left(90^{\circ}+45^{\circ}\right)$ from vertical surface, 3$)$ the side-fins is selected to be up to the half of the window width (W), and 4) the louvers are set apart by $0.9 \mathrm{~m}$ and allowed to project incrementally in a step of $0.25 \mathrm{~m}$ from $0.25-1.0 \mathrm{~m}$. It worth notice that the glazing materials construction is set to $6 \mathrm{~mm}$-low-e and $12 \mathrm{~mm}$ air gap for all cases. Also, the frame and divider materials are chosen to be aluminum and represent $5 \%$ of the total window area. A list of these design parameters is given in Table 1 . These design parameters generate 1104 possible solutions for each orientation making a total of 4416 possible of total solutions (search space).

Table 1: Design parameters values.

\begin{tabular}{cccccc}
\hline No. & Variable & LB & UB & $\begin{array}{c}\text { Step- } \\
\text { size }\end{array}$ & $\begin{array}{c}\text { No. } \\
\text { Steps }\end{array}$ \\
\hline 1 & Overhang tilt $\left({ }^{\circ}\right)$ & 90 & 135 & $5^{\circ}$ & 10 \\
\hline 2 & overhang projection $(\mathrm{m})$ & 0 & $\mathrm{H} / 2$ & $5 \%$ & 10 \\
\hline 3 & side-fins projection $(\mathrm{m})$ & 0 & $\mathrm{~W} / 2$ & $5 \%$ & 10 \\
\hline 4 & two louvers $(\mathrm{m})$ & 0 & 1.0 & 0.25 & 4 \\
\hline
\end{tabular}

\section{Objectives Functions}

In this study, the first objective function is to minimize the annual cooling and heating consumptions of the studied office. The second objective function is to increase the daylighting illuminance to reduce electrical lighting. The objective functions of the annual energy consumption, $\mathrm{f}(\mathrm{x})$ and $\mathrm{f}(\mathrm{y})$, can be expressed as follows:

$$
\begin{aligned}
& f(x)=\left[Q_{c}(x)+Q_{h}(x)\right] / 3.6 \times 10^{6} \\
& f(y)=\left[E_{\text {Daylighting }}(x)\right]
\end{aligned}
$$


$\mathrm{Q}_{\mathrm{c}}(\mathrm{x})$ and $\mathrm{Q}_{\mathrm{h}}(\mathrm{x})$ are the room' annual cooling and heating energy consumptions $(\mathrm{J})$, respectively. The denominator is a factor to convert the energy to $\mathrm{kWh}$. $E_{\text {Daylighting }}(x)$ is the room' daylighting (lux).

The two competing objectives are; minimizing the heating and cooling consumptions, and maximizing the natural light (daylighting). The relation is formed in Eq. 3.

$$
f(x y)=f_{\min }(x)+f_{\max }(y)
$$

\section{The Modelled Zone}

The geographic location and the orientation of the building have a profound effect on the solar gain by the windows and walls. The façade that received the largest amount of radiation is dependent on the latitude and the season under consideration. Since the cooling load is the main electrical consumption in hot climate countries, the focus is given to the façade that received the maximum radiation from the sun during long days of summer. In the northern part of the equator, the facade facing west receives the largest solar radiation, during the summer season whereas the façade facing south receives the largest solar radiation during winter and a full year. The space considered in this study is a single office in a midfloor of a multistory commercial building in the State of Kuwait. The dimensions of the representative room that used to optimize window's shading devices are illustrated in Figure 2. The exterior wall was fixed to be $4.2 \mathrm{~m}$ wide and $4.0 \mathrm{~m}$ heights. For the glazing feature, a double low-e $6 \mathrm{~mm}$ clear glass with $12 \mathrm{~mm}$ air is used (the common practice construction for a new office building in Kuwait). The indoor temperatures were set at $21^{\circ} \mathrm{C}$ and $23^{\circ} \mathrm{C}$ for the winter and summer seasons, respectively.

\section{Local Weather Data}

In this work, the weather data for Kuwait City $\left(29.22^{\circ}\right.$ Latitude, $47.98^{\circ}$ Longitude, and $55 \mathrm{~m}$ elevation) has been selected as the external weather of the simulated office (typical metrological year, TMY). The design days of summer and winter seasons in Kuwait, as per the Energy Conservation Code of Practice (MEW-R-6, 2014), are given in Table 2.

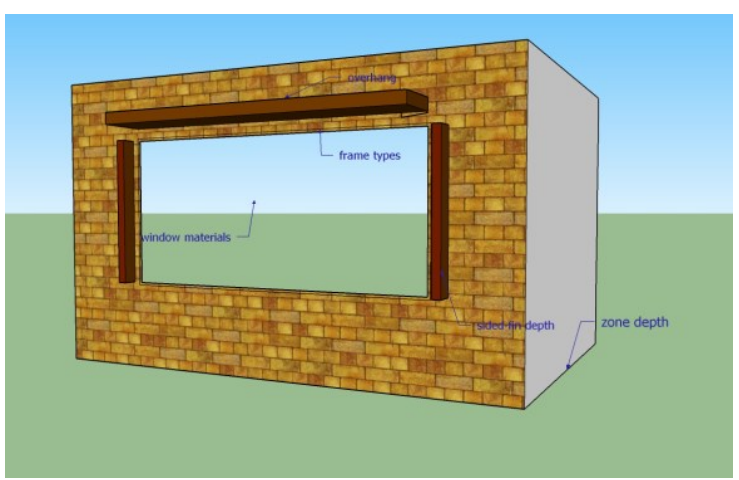

Figure 2: Schematic of the office design parameters.

Table 2: Design days in Kuwait.

\begin{tabular}{c|c|c|c}
\hline $\begin{array}{c}\text { Design } \\
\text { Day }\end{array}$ & $\begin{array}{c}\text { Dry-bulb } \\
\text { temp. }\end{array}$ & $\begin{array}{c}\text { Daily Range } \\
\text { Temp. }\left({ }^{\circ} \mathrm{C}\right)\end{array}$ & $\begin{array}{c}\text { Month/ } \\
\text { Day }\end{array}$ \\
\hline Summer & $\mathbf{4 8}$ & 13 & $7 / 21$ \\
\hline Winter & 5.6 & 7 & $1 / 21$ \\
\hline
\end{tabular}

The data of these design days, together with the design supply temperatures, are used to automatically size the heating, ventilating, and air conditioning (HVAC) systems using EnergyPlus simulation program. However, building response to the auto-sized HVAC system is considered over a complete meteorological year, in order to accurately calculate the total building energy consumption. In this study, the ideal load template available in EnergyPlus is used "HVACTemplate: Zone: IdealLoadsAirSystem" to calculate the required heating and cooling demands on each calculating step for the zone with a design factor of 1.25 for heating and 1.15 for cooling.

\section{Set-up of Numerical BSOT Process}

The EnergyPlus building simulation program is utilized in this study to simulate the zone load. An EnergyPlus input file (IDF) that represents the baseline model is developed and tested. The results of this model are used after that to evaluate optimum solutions. The search for solutions is started by setting the upper and lower limits and the stepwise in the considered design variables. This is done using the jEPlus tool (Zhang, 2009), which allows changing the values specified for each of the design parameters within their limits. Values of these parameters are fed automatically to the IDF file.

Once the project is defined in jEPlus, the tool (jEPlus+EA) is used to perform the Genetic Algorithms, GA, optimization process (Zhang, 2012). The jEPlus+EA process was executed remotely through the allocated server. The entire process is illustrated in Figure 3. The steps of research methodology that are used in this numerical simulation can be summarized as:

- Define the studied zone using EnergyPlus to create the IDF file with the following inputs:
a. weather file
b. zone dimensions
c. window dimensions
d. internal load
e. constructions materials
f. occupant activity and internal load schedules
g. daylighting and glare set values

- Set the lower bound (LB), upper bound (UB) and the stepwise of the design parameters using the jEPlus tool.

- Select one of the shading options.

- Find the optimum solutions within the search space using the jEPlus+EA tool.

- Repeat the procedures for each orientation; see Figure 2 .

The optimization run is performed using the Nondominated Sorting Genetic Algorithm II (NSGA-II) implemented in jEPlus+EA. The specifications of the algorithm settings include:

- Integer encoding of the design variables

- Population size 15

- Binary tournament selection

- Hybrid (single point, uniform, and arithmetic) crossover operator, with a $100 \%$ crossover rate. 


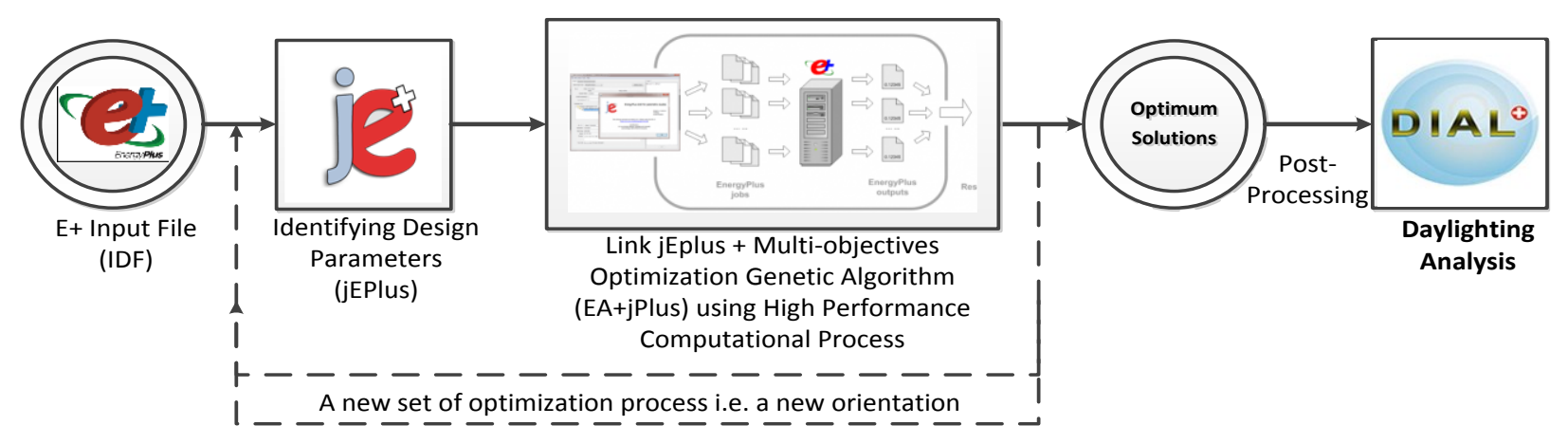

Figure 3: Numerical SOT process set-up.

- Random mutation with $20 \%$ mutation rate.

- Pareto archived elitism operator

- Evolution is limited to 100 generations for each run.

The selection of algorithm settings is dependent on the characteristics of the problem. Based on the experience of optimization problems in building design and the results of the pilot run, this setting is considered to perform well (Wright and Alajmi, 2016).

\section{Climate-based Daylighting Metrics Assessment}

Dynamic or climate-based daylighting assessment become a useful tool to evaluate the harvesting of natural light in a space. There are many metrics to evaluate the daylighting presence in a space such as Spatial Daylighting Autonomy (sDA), and Useful Daylighting Illuminance (UDI).

The sDA is defined as a percentage of the task area that meets a minimum daylight illuminance level for a given fraction of operating hours per year, i.e., that meets a defined daylight autonomy level.

The recommended thresholds in this research are 300 lux and $80 \%$ of operating hours, daily from 7 am to $3 \mathrm{pm}$ local time (incorporating daylight savings time), and the sDA value is given in percent. sDA is calculated according to follows:

$$
S D A_{300,50 \%}=\frac{E \geq 300 l x \text { for at least } 50 \% \text { of operating hours }}{\text { Overall analysis area }}
$$

According to the Illuminating Engineering Society (IES), the target values for the spatial daylight autonomy are as follows:

- sDA300, 50\% $\geq 55 \%$ : nominally acceptable daylight sufficiency,

- sDA300, 50\% $\geq 75 \%$ : preferred daylight sufficiency.

The other dynamic daylighting assessment that was used in this research is useful daylighting illuminance (UDI). It is UDI is the annual occurrence of daylight illuminances across the workplace within a given range (Nabil, A. and J. Mardaljevic, 2005). This range was defined to encompass "useful illuminances for occupants" from a comprehensive review of occupant's behavior with lighting with dimming and blinds. Unlike electric lighting, where the target is of $500 \mathrm{~lx}$, some studies showed that daylight around $100 \mathrm{~lx}$ can be sufficient and illuminances higher than 2000 to $2500 \mathrm{~lx}$ lead to a visual discomfort.

To summarize four categories were defined:

- Daylight illuminances less than $100 \mathrm{~lx}$ are not sufficient.

- Daylight illuminances between 100-500 1x are generally sufficient and can be reinforced by electric lighting.

- Daylight illuminances between 500-2000/2500 lx are autonomous towards electric lighting.

- Daylight illuminances higher than 2000/2500 lx lead to visual discomfort.

Limits defined above can be discussed depending on the local activities and occupants. Anyway, the scheme is more important than the exact value, and the useful UDI is considered as the collection of illuminances between 100 and 2000/2500 lx. As explained above, there are several ranges to classify satisfaction of illuminance level: not sufficient, useful and too high. Moreover, in the useful UDI range, there are two complementary UDI ranges: supplementary and autonomous.

All ranges are defined as follows:

- UDI-f: UDI fell-short: The illuminance is less than $100 \mathrm{~lx}$,

- UDI-s: UDI supplementary: The illuminance is greater than 100 lx and less than 300/500 lx,

- UDI-a: UDI autonomous: The illuminance is greater than 300/500 lx and less than 2000/2500 lx,

- UDI-e: UDI exceeded: The illuminance is greater than 2000/2500 lx.

So in this research UDI-a was used to compare the optimum solutions of the shading devices.

\section{Results and Discussion}

Although the two objectives functions are set for the optimum solutions obtained by the BSOT process, the optimum solutions should not be dominated by one of the objective functions. When the BSOT process converged with no domination of either objective functions, the solution is called Pareto-front solutions (Deb, 2001).

These solutions are presented by red points in Figure 4 . Pareto-front solutions are survived for many generations during the BSOT process. On the other hand, the blue 
points (Figure 4) are those solutions produced for the last generation run. They have not matched the Pareto-front solutions produced by the BSOT process.

Table 3 lists the optimum solutions of all examined shading options. In Table 3, there are various optimum solutions for the East orientation all the tested shading options showing good performance concerning energy consumption, only $3 \%$ differences. However, the other orientation dominated by the overhang with sided-fin shading device. Thus, a climate-based daylighting assessment is employed for each orientation only to select among those best solution, see Table 3 . As a result of the daylighting assessment, the simple overhang showed the best performance from the perspective of energy, and daylighting availability in the East, as well as its, eases of construction. Whereas in the other orientations (South, North, and West), the overhang with sided-fins showed far better results in respect of energy, more than $10 \%$, which make the daylighting assessment is limited to them.

\section{Conclusion}

The main objectives of this paper are to minimize energy consumption and to maximize daylighting availability of three different window's attachments. The three-fixed window's shading options are overhang with sided-fins, simple overhang, and louvers. Each of which has been parameterized to find the optimum configuration using a Genetic Algorithm to look for the optimum solutions within the search space. Interestingly, the optimum shading options on the East orientation required a further assessment to select among the close best optimum solutions (within 3\% difference). In this side (East), the simple overhang showed an overall best option from both energy and daylighting perspectives. However, the overhang with sided-fins solution dominated the other orientation (South, West, and North).
Table 3: Optimum solutions of window's attachment for each orientation.

\begin{tabular}{|c|c|c|c|c|c|}
\hline Type & $\begin{array}{l}\text { Over } \\
\text { hang. } \\
\text { Proj. } \\
\text { (m) }\end{array}$ & $\begin{array}{c}\text { Lou } \\
\text { vers } \\
\text { Proj. } \\
\text { (m) } \\
\end{array}$ & $\begin{array}{c}\text { Overhang } \\
\text { Tilt } \\
\text { Angle }\left(^{\circ}\right)\end{array}$ & $\begin{array}{l}\text { Fin } \\
\text { Proj. } \\
\text { (m) }\end{array}$ & $\begin{array}{c}\text { Energy } \\
\text { saving } \\
\%\end{array}$ \\
\hline \multicolumn{6}{|c|}{ East } \\
\hline $\begin{array}{l}\text { Overhang } \\
\text { with } \\
\text { sided-fins }\end{array}$ & 1.2 & - & 130 & 1.0 & 27 \\
\hline $\begin{array}{l}\text { Simple } \\
\text { overhang }\end{array}$ & 1.3 & - & 135 & - & 25 \\
\hline louvers & - & $1 \mathrm{~m}$ & - & - & 24 \\
\hline \multicolumn{6}{|c|}{ North } \\
\hline $\begin{array}{l}\text { Overhang } \\
\text { with } \\
\text { sided-fins }\end{array}$ & 1.2 & - & 130 & 1.1 & 14 \\
\hline \multicolumn{6}{|c|}{ West } \\
\hline $\begin{array}{l}\text { Overhang } \\
\text { with } \\
\text { sided-fins }\end{array}$ & 1.2 & - & 130 & 1.3 & 28 \\
\hline $\begin{array}{l}\text { Simple } \\
\text { Overhang } \\
\end{array}$ & 1.1 & - & 130 & - & 19 \\
\hline \multicolumn{6}{|c|}{ South } \\
\hline $\begin{array}{l}\text { Overhang } \\
\text { with } \\
\text { sided-fins }\end{array}$ & 1.2 & - & 130 & 1.3 & 36 \\
\hline $\begin{array}{l}\text { Simple } \\
\text { overhang }\end{array}$ & 0.9 & - & 125 & - & 20 \\
\hline
\end{tabular}

\section{Acknowledgment}

The author would like to express his gratitude to Kuwait Foundation for the Advancement of Science (KFAS) for funding this work to be presented in the IBPSA2019 conference.

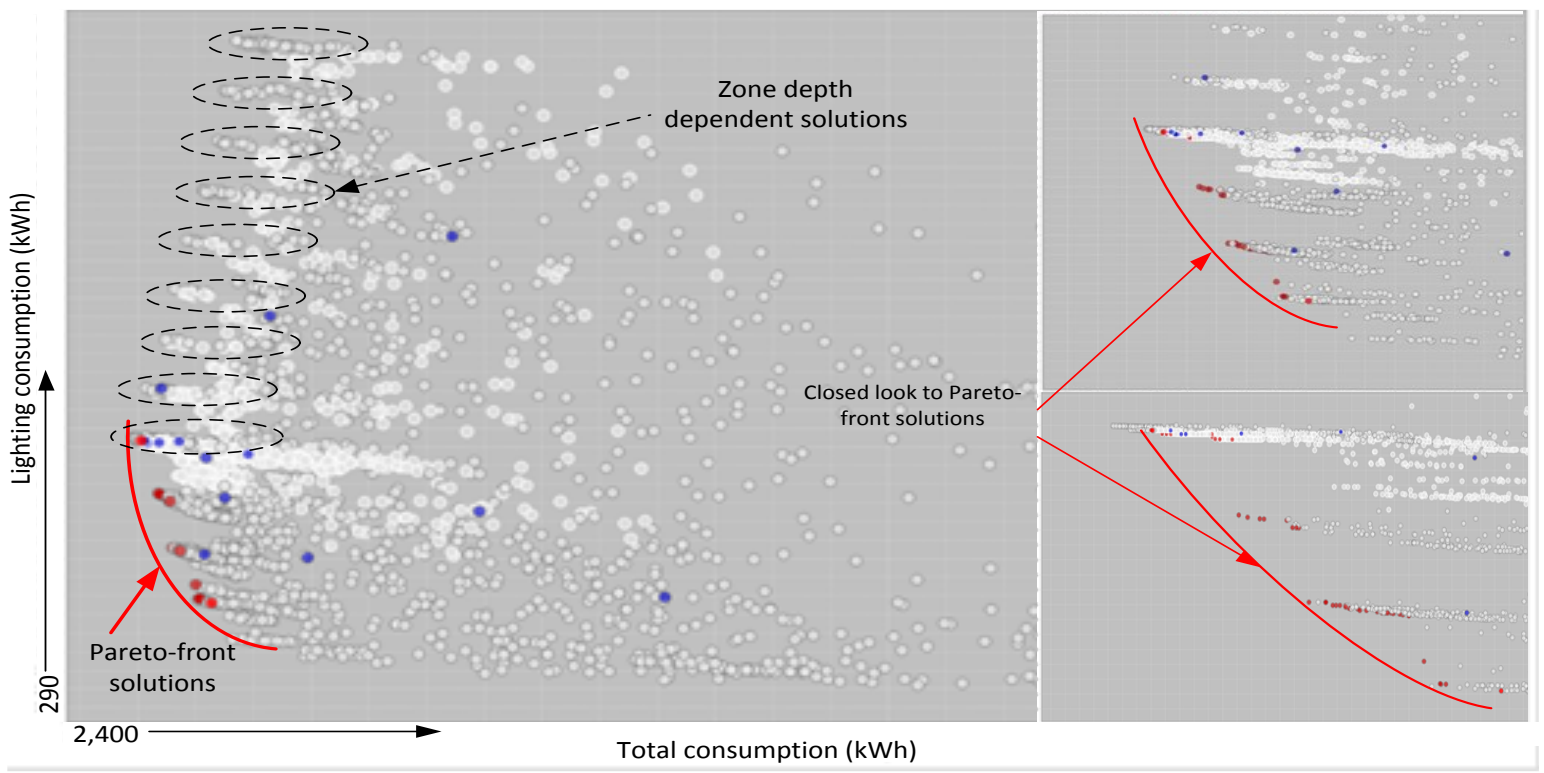

Figure 4: Pareto-front of optimum solutions of the two main objectives shown in red dots.

Table 4: Climate-based daylighting assessment of the East orientation. 


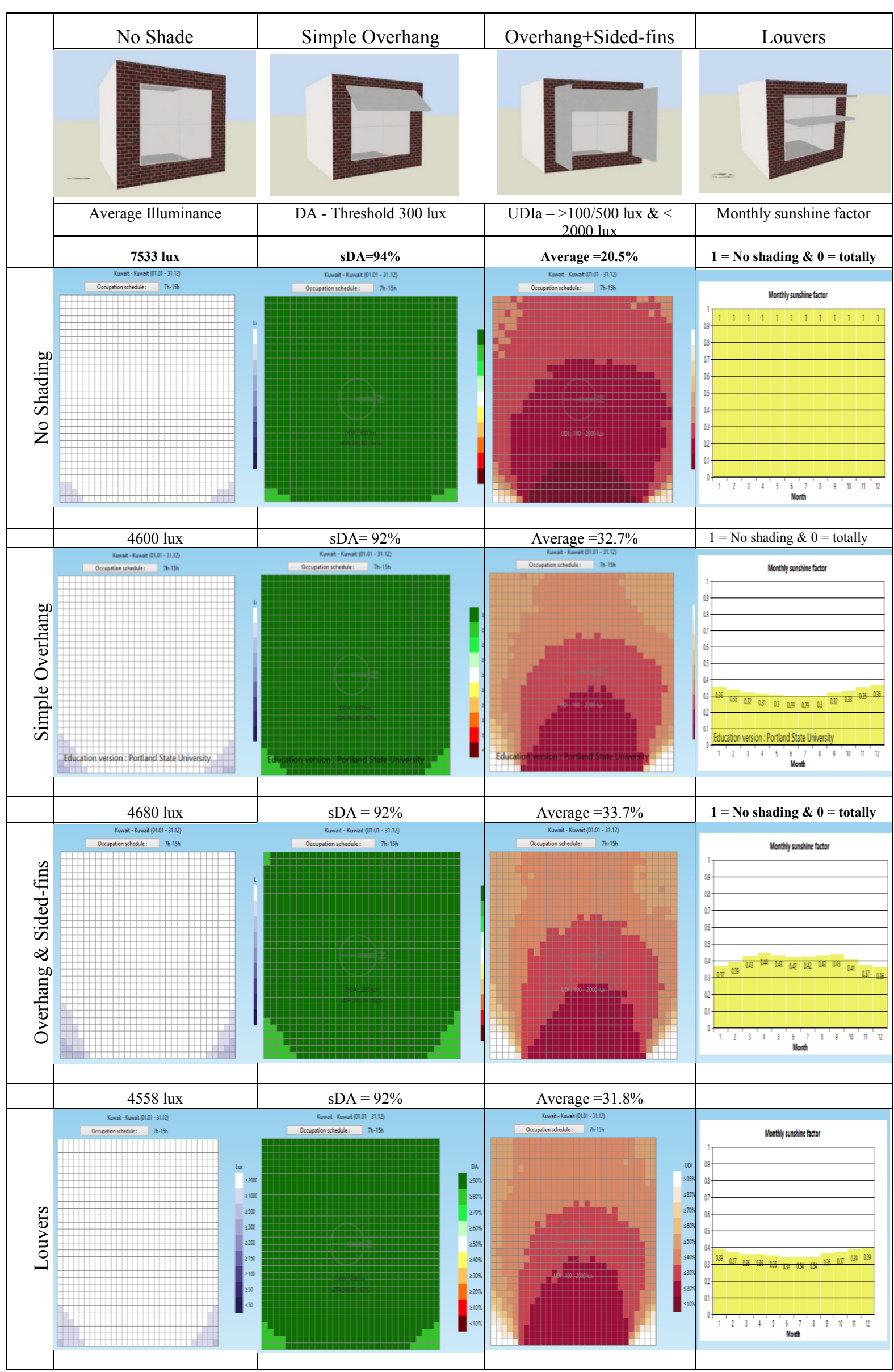




\section{References}

Alajmi, A. and J. Wright (2014). Selecting the most efficient genetic algorithm sets in solving unconstrained building optimization problem, International Journal of Sustainable Built Environment, 3(1), 18-26.

Caldas, L., and L. Norford (2001). Architectural constraints in a generative design system: Interpreting energy consumption levels, 7th International IBPSA Conference: Building Simulation, IBPSA, 1397-1404.

Carlucci, S., F. Causone, F. De Rosa and L. Pagliano. (2015). A review of indices for assessing visual comfort with a view to their use in optimization processes to support building integrated design, Renewable and Sustainable Energy Reviews, 47, 1016-1033.

Deb, K., 2001. Multi-Objective Optimization using Evolutionary Algorithms. Chichester : John Wiley \& Sons.

Echenagucia, T.M., A. Capozzoli, Y. Cascone and M. Sassone (2015). The early design stage of a building envelope: Multi-objective search through heating, cooling, and lighting energy performance analysis, Applied Energy, 154,577-591.

Goia, F. (2016). Search for the optimal window-to-wall ratio in office buildings in different European climates and the implications on total energy saving potential, Solar Energy, 132, 467-492.

Goldberg, D.E. (1989). Genetic Algorithm in search, optimization, and machine learning. Second ed. New York: Addison-Wesley Publishing Company, Inc.

Kheiri, F. (2013). The relation of orientation and dimensional specifications of window with building energy consumption in four different climates of Ko ppen classification. Researcher 5, 107-115.

Lee, J.W., H.J. Jung, J.Y. Park, J.B. Lee and Y. Yoon (2013). Optimization of building window system in Asian regions by analyzing solar heat gain and daylighting elements. Renewable Energy 50, 522-531.

MEW (Ministry of Electricity and Water) (2007). Report on the prediction of energy consumption, Kuwait.

MEW (Ministry of Electricity and Water) (2014). Energy conservation program, Code of practice MEW/R6/2014, Kuwait.

Nejat, P., F. Jomehzadeh, M. Taheri, M. Gohari and M. MZiA (2015). A global review of energy consumption, $\mathrm{CO} 2$ emissions and policy in the residential sector (with an overview of the top ten $\mathrm{CO} 2$ emitting countries). Renewable and Sustainable Energy Reviews, 43, 843862.

Olsen, E.L., and Q. Chen (2003). Energy consumption and comfort analysis for different low-energy cooling systems in a mild climate. Energy and Buildings, 35(6), 560-571.
Özkan, D.B. and C. Onan (2011). Optimization of insulation thickness for different glazing areas in buildings for various climatic regions in Turkey, Applied Energy, 88(4), 1331-1342.

Peel, M.C., B.L. Finlayson and T.A. McMahon (2007). Updated world map of the Ko"ppen-Geiger climate classification. Hydrol. Earth Syst. Sci. 11, 1633-1644.

Pérez-Lombard, L., J. Ortiz, and C. Pout (2008). A review on buildings energy consumption information, Energy and buildings 40(3), 394-398.

Wetter, M. and J Wright (2003). Comparison of a generalized pattern search and genetic algorithm optimization method. 8th International IBPSA Conference: Building Simulation, IBPSA, 1401-1408.

Wright, J. and Alajmi, A. (2016). Efficient Genetic Algorithm sets for optimizing constrained building design problem, International Journal of Sustainable Built Environment, 5(1), 123-131.

Zhang, Y. (2012). Use jEPlus as an efficient building design optimisation tool, CIBSE ASHRAE Technical Symposium, Imperial College, London UK - 18-19 April 2012.

Zhang, Y. (2009). 'Parallel' EnergyPlus and the development of a parametric analysis tool, IBPSA BS2009, 27-30 July 2009, Glasgow, UK.

IES, Illuminating Engineering Society, (2012). IES LM-8312, Approved Method: IES Spatial Daylight Autonomy (sDA) and Annual Sunlight Exposure (ASE).

Nabil, A. and J. Mardaljevic, Useful daylight illuminance: a new paradigm for assessing daylight in buildings. Lighting Research \& Technology, 2005. 37(1): p.41-59. 